\title{
PERENCANAAN KONSEP DESAIN KLOJEN KULINER HERITAGE DI KOTA MALANG
}

\author{
Putri Herlia Pramitasari \\ Dosen Prodi Arsitektur, Fak. Teknik Sipil dan Perencanaan, ITN Malang \\ e-mail: putri herlia@lecturer.itn.ac.id \\ Maria Istiqoma \\ Dosen Bahasa Inggris, Fak. Teknik Sipil dan Perencanaan, ITN Malang \\ e-mail: maria istiqoma@lecturer.itn.ac.id \\ Sri Winarni \\ Dosen Prodi Arsitektur, Fak. Teknik Sipil dan Perencanaan, ITN Malang \\ e-mail: sriwinarni@lecturer.itn.ac.id
}

\begin{abstract}
ABSTRAK
Konsep wisata urban heritage pada Kelurahan Klojen layak diangkat sebagai daya tarik pariwisata Kota Malang sebagai upaya memperkuat citra kota. Banyaknya potensi fisik dan non-fisik kawasan menjadikan kawasan objek studi sangat potensial dikembangkan menjadi salah satu pilihan kawasan wisata dalam kota. Pelaksanaan pendampingan ini ditujukan sebagai upaya keberlanjutan pengembangan fisik kawasan dalam bentuk perencanaan konsep desain Klojen kuliner heritage pada area objek studi. Metode perancangan arsitektur rasional-pragmatis dijadikan sebagai pendekatan konsep desain. Penataan fisik kawasan objek studi sepanjang Jl. Trunojoyo hingga Jl. Dr. Sutomo dijadikan sebagai ruang terbuka aktif, edukatif, rekreatif, dan inovatif untuk memperkuat citra kawasan sebagai Klojen Kuliner Heritage. Strategi penataan konsep desain fisik kawasan difokuskan pada pemberian gerbang masuk destinasi wisata, shelter, billboard, elemen penanda, street furniture bernuansa heritage, perbaikan pedestrian khususnya area sepanjang Jl. Trunojoyo, serta pemberian booth kuliner dan souvenir khas Malang, spot-spot foto, dan panggung kreasi sebagai area atraksi di area Jl. Dr. Sutomo. Upaya perencanaan konsep desain Klojen kuliner heritage harus dapat memenuhi kriteria urban heritage tourism sebagai strategi memperkuat city branding Kota Malang sebagai kota pariwisata dan dapat berjalan sinergi melalui keterlibatan para stakeholders.
\end{abstract}

Kata kunci : wisata urban heritage, Klojen Kuliner Heritage, ruang terbuka aktif

\section{ABSTRACT}

Urban heritage tourism concept in Klojen Village deserves as the tourism attraction of Malang City as an effort to strengthen the city's image. The number of physical and non-physical potentials of the area makes the study object very potential to be developed into one of the choices of tourist areas in the city. The implementation of this assistance is intended as an effort the sustainability of physical development area in the form of

PAWON: Jurnal Arsitektur, Nomor 02 Volume III, Juli-Desember 2019, ISSN 2597-7636 
the culinary heritage design concept of object study. The rational-pragmatic architecture design method is used as a design concept approach. Physical arrangement of study object area along Jl. Trunojoyo to Jl. Dr. Sutomo was used as an active, educative, recreational and innovative open space to strengthen the image of the region as Klojen Culinary Heritage. The strategy for structuring the concept of the area's physical design is focused on the provision of entry gate for tourist destinations, shelter, billboards, markers, heritage street furniture, pedestrian repairs, especially areas along Jl. Trunojoyo, as well as providing unique culinary booths and souvenirs, photo spots, and stage creations as attractions in the area of Jl. Dr. Sutomo. Efforts the design concept of Klojen heritage culinary must be able to meet the criteria of urban heritage tourism as a strategy to strengthen the city branding of Malang City as a tourism city and to be able to run synergies through the involvement of stakeholders.

\section{Keywords : urban heritage tourism, Klojen Culinary Heritage, active open space}

\section{PENDAHULUAN}

Kawasan sepanjang Jl. Trunojoyo hingga Jl. Dr. Soetomo, Kelurahan Klojen, Kota Malang diarahkan menjadi salah satu sentra wisata kuliner heritage dengan menggunakan pendekatan konsep urban heritage tourism. Konsep ini tepat dikembangkan pada kawasan ini karena adanya kesatuan fungsi edukatif, rekreatif, dan pelestarian Kota Malang secara komprehensif.

Konsep urban heritage tourism dinilai paling tepat menjadi pertimbangan dasar dalam pendekatan konsep desain pengembangan fisik kawasan. Hal ini disebabkan lokasi objek studi yang sangat strategis terletak di tengah Kota Malang dan banyak dikelilingi bangunan sekolah dan perkantoran, fasilitas layanan umum (Rumah Sakit, stasiun, pasar), wahana wisata dalam kota, maupun deretan bangunan kolonial yang memiliki khas nuansa heritage.

Perencanaan desain kawasan objek studi perlu dirancang sesuai dengan kebutuhan pengguna dan bersinergi dengan kebijakan Pemerintah agar tercipta desain tata ruang yang terstruktur dan tersistem dengan baik untuk memperbaiki permasalahan fisik dan non-fisik kondisi eksisting kawasan yang masih kurang optimal.

Perencanaan konsep desain urban heritage tourism melalui strategi penataan lansekap dan pemenuhan infrastruktur yang layak dan nyaman pada area objek studi menjadi fokus kajian kali ini. Konsep desain fisik kawasan yang dibuat diharapkan dapat bersinergi pula dengan aspek nonfisik kawasan agar tercapai keberlanjutan pembangunan. 


\section{TINJAUAN PUSTAKA}

Kelurahan Klojen, khususnya kawasan sepanjang Jl. Trunojoyo hingga Jl. Dr. Sutomo sangat potensial dijadikan sebagai sentra wisata kuliner heritage Kota Malang sebagai salah satu aset wisata unggulan (Pramitasari, P. H., et al. 2018).

Keuntungan yang didapatkan dari area yang memiliki city branding, diantaranya daerah tersebut akan memiliki persepsi yang baik dan dikenal luas, memiliki tujuan spesifik, dianggap tepat sebagai tujuan wisata, tempat investasi, penyelenggaraan kegiatan, bahkan tujuan tempat tinggal, maupun dipersepsikan sebagai area dengan keamanan dan kesejahteraan yang tinggi (Prabowo, B. N. 2015). Oleh karena itu, diperlukan perencanaan konsep desain pada area objek studi sebagai salah satu destinasi wisata heritage kota.

Patil, R., dan Patil, V. (2016) memaparkan teori Lynch tentang bentuk kota yang baik, yaitu kota yang dapat menghasilkan permukiman yang baik dan berkualitas, dimana memungkinkan terjadinya pembangunan secara berkelanjutan melalui keterbukaan dan koneksi. Lynch menyajikan lima dimensi kinerja, yaitu vitalitas, rasa, kecocokan, akses, dan kontrol. Lynch juga menyajikan dua "meta-kriteria", yaitu efisiensi dan keadilan.

Adapun pendekatan desain perkotaan menurut Meng, X. W. dan Setoguchi, T. (2010) dapat dijabarkan sebagai berikut:

a. Ruang terbuka bisa menjadi salah satu pilihan tempat yang terbaik dalam mendorong kegiatan yang bersifat publik dengan fasilitas plaza dan pedestrian.

b. Desain perkotaan harus menyesuaikan iklim setempat.

Penataan infrastruktur juga berperan penting dalam pencapaian keberhasilan perencanaan urban heritage tourism. Menurut Hong, J. dan Shin, S. (2016) dalam mendirikan infrastruktur seperti ruang publik, harus mengadopsi kebijakan-kebijakan terkait dengan model jaringan kota, yang menekankan berbagai fasilitas dasar perkotaan, dan memperkuat sinergi dari berbagai kebijakan yang berkaitan dengan pembangunan perkotaan, arsitektur lansekap dan sarana prasarana.

Keberlangsungan aktivitas sosial budaya yang unik dan spesifik turut menjadi penentu keberhasilan kawasan urban heritage tourism. Menurut Dimyati (2011) keberadaan kelompok aktivitas ekonomi masyarakat pada suatu lingkungan dapat mempengaruhi perkembangan dan perubahan bentuk dari lingkungan fisik maupun lingkungan sosio-ekonomi. Masyarakat di perkotaan pada umumnya mempunyai sistem hubungan sosial dalam melakukan kegiatan-kegiatan ekonomi. Dengan perkembangan ekonomi yang semakin meningkat perlu adanya usaha dalam menciptakan kualitas 
lingkungan yang baik dan tertata dalam rangka meningkatkan kehidupan yang berkelanjutan.

\section{METODE PERANCANGAN}

Metode perencanaan konsep desain fisik kawasan objek studi dilakukan melalui pendekatan rasional-pragmatis yang memenuhi aspek urban heritage tourism dari aspek tatanan lansekap dan infrastruktur. Teknik pengumpulan data dilakukan melalui pengumpulan data eksisting tapak, iklim, peraturan dan wilayah setempat, sirkulasi dan aksesibilitas, view, vegetasi, dan jaringan utilitas kawasan objek studi. Selanjutnya, data tersebut dianalisis terkait aspek fungsi dan tata ruang, desain arsitektural, tatanan lansekap, serta infrastruktur kawasan objek studi. Deskripsi analisis dan sintesis dari setiap produk gambar juga ditambahkan untuk memperjelas konsep desain. Instrumen pengambilan data menggunakan kamera, media kertas, dan alat tulis untuk sketsa untuk selanjutnya diproses menggunakan software program AutoCAD dan SketchUp untuk pembuatan gambar konsep desain arsitektur secara digital.

\section{HASIL DAN PEMBAHASAN}

Aspek urban heritage tourism menjadi unsur pokok yang dijadikan pendekatan konsep desain pada kawasan objek studi. Penataan lansekap (fungsi dan tata ruang, dan desain arsitektural kawasan) serta infrastruktur kawasan (aksesibilitas dan fasilitas umum) dilakukan dengan memperhatikan kondisi eksisting tanpa mengabaikan hasil evaluasi kekuatan, kelemahan, peluang atau potensi, dan ancaman dari kajian objek studi sebelumnya.

Konsep perencanaan desain dibuat secara makro dan mikro di sepanjang kawasan dengan mengoptimalkan ruang terbuka pasif menjadi ruang terbuka aktif yang bersifat edukatif, rekreatif, dan unik dengan tetap mempertahankan nuansa heritage yang menjadi citra kuat pada kawasan objek studi.

Perencanaan block plan konsep desain dirancang di sepanjang kawasan objek studi seperti terlihat pada Gambar 1. Penataan kawasan secara makro dirancang dengan adanya perencanaan desain titik-titik gerbang masuk, shelter, penempatan giant billboard, serta elemen penanda. Perencanaan elemen arsitektural tersebut dioptimalkan dengan memberikan sekuens yang berbeda pada tiap titik. 

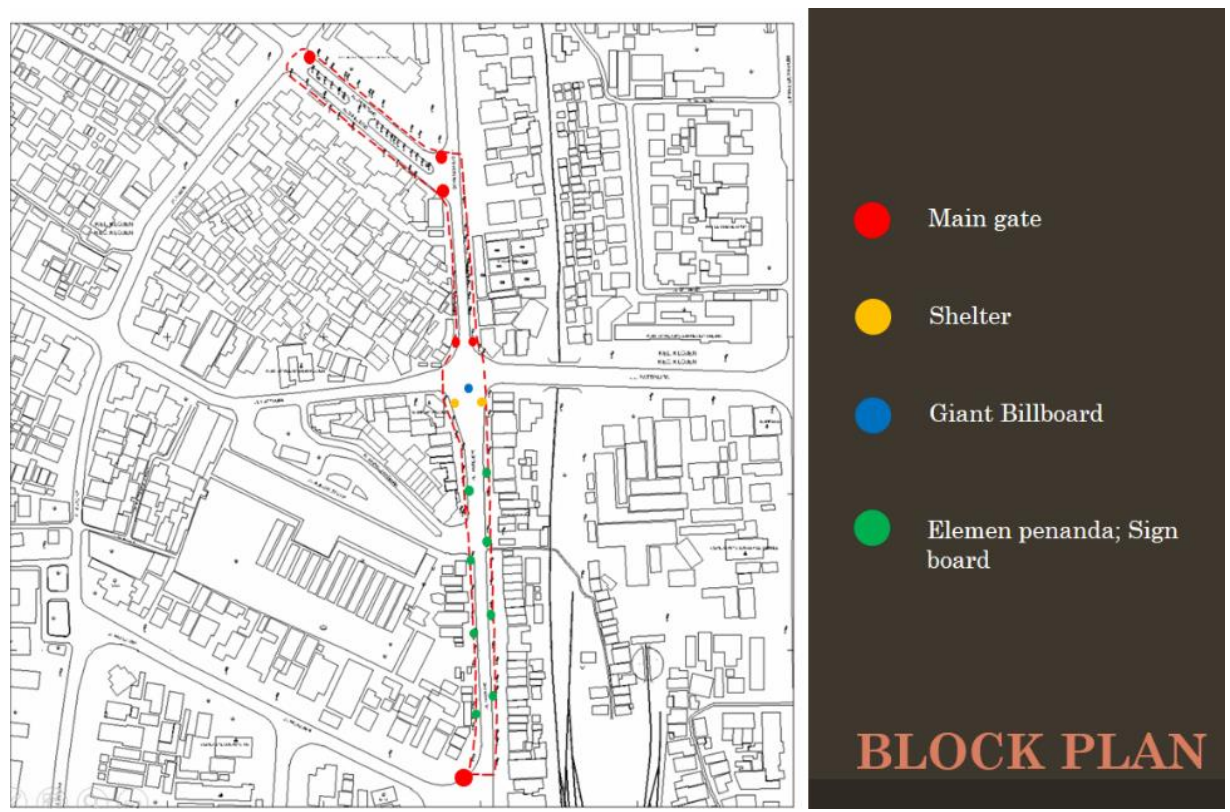

\section{Gambar 1. Konsep perencanaan signage Klojen Kuliner Heritage \\ Sumber: Analisis penulis (2018)}

Konsep perencanaan kawasan Jl. Dr. Sutomo dijadikan sebagai area kuliner dan oleh-oleh khas Malang dengan penyediaan area booth dan panggung kreasi di sisi utara dan area makan di sisi selatan sebagaimana dapat dilihat pada gambar 2 .

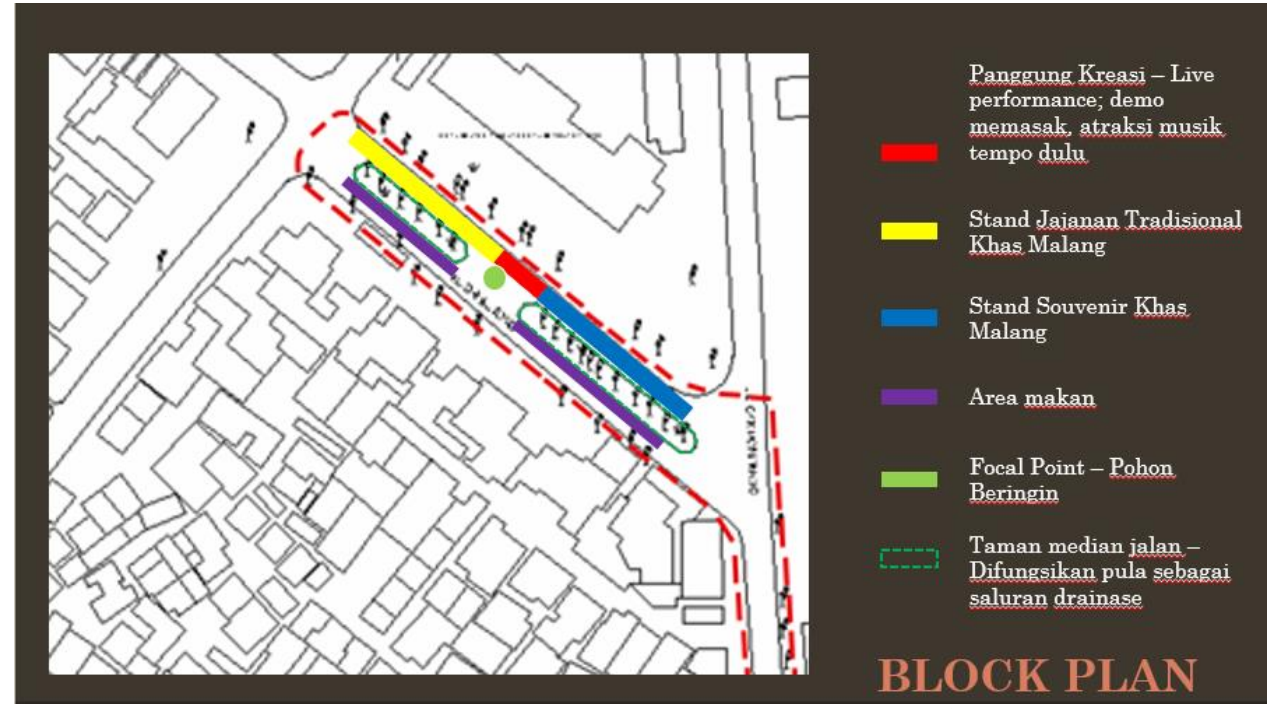

Gambar 2. Konsep perencanaan kawasan JI. Dr. Sutomo

Sumber: Analisis penulis (2018) 
Gerbang masuk utama diletakkan pada pertigaan Jl. Padjajaran dengan Jl. Trunojoyo dengan mengangkat tema kuliner dan heritage untuk memperkuat citra kawasan sebagai Klojen Kuliner Heritage.
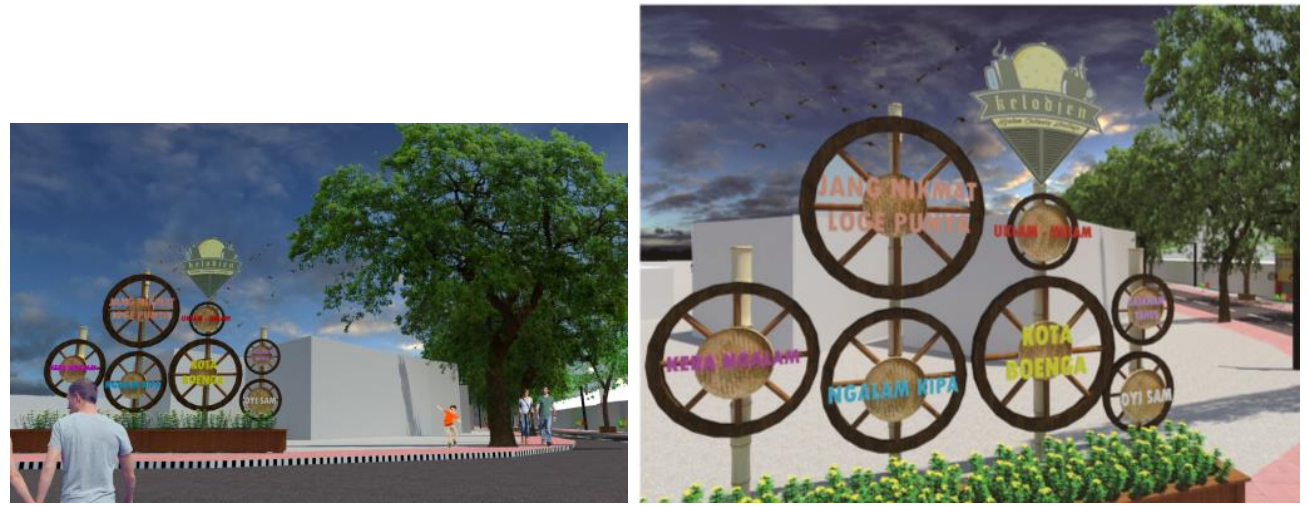

Gambar 3. Rancangan Main Gate Awal JI. Trunojoyo Sumber: Analisis penulis (2018)

Pedestrian (jalur pejalan kaki) sepanjang Jl. Trunojoyo hingga Jl. Dr. Sutomo didesain dengan motif menarik, pemberian warna yang cerah, serta terdapat penanda jalur untuk kaum diffable. Penyediaan tempat sampah dengan membedakan jenis sampah organik, anorganik, dan B3 dengan desain unik dan ditempatkan tiap jarak minimal 20-50 meter juga dijadikan konsep inovasi dan berfungsi edukatif untuk menciptakan desain ruang terbuka yang interaktif dan ramah lingkungan.

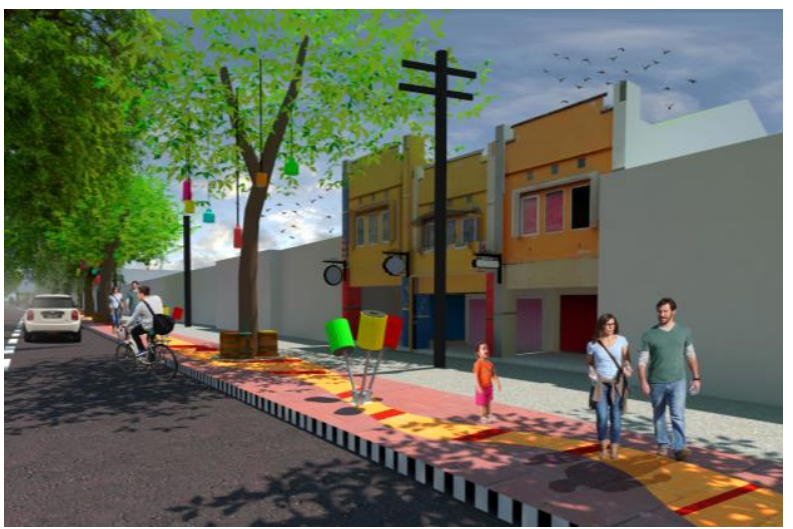

Gambar 4. Rancangan Pedestrian pada Jl. Trunojoyo Malang Sumber: Analisis Penulis (2018)

Perbaikan jalur pedestrian yang rusak, pewarnaan kembali fasade ruko, serta pemberian papan nama di setiap ruko bernuansa heritage turut memperkuat konsep desain Klojen Kuliner Heritage di sepanjang Jl. Trunojoyo hingga pertigaan JI. Dr. Sutomo. Pemerintah dapat berkolaborasi 
dengan pihak industri, komunitas atau CSR terkait agar pembangunan fisik dapat berkelanjutan.

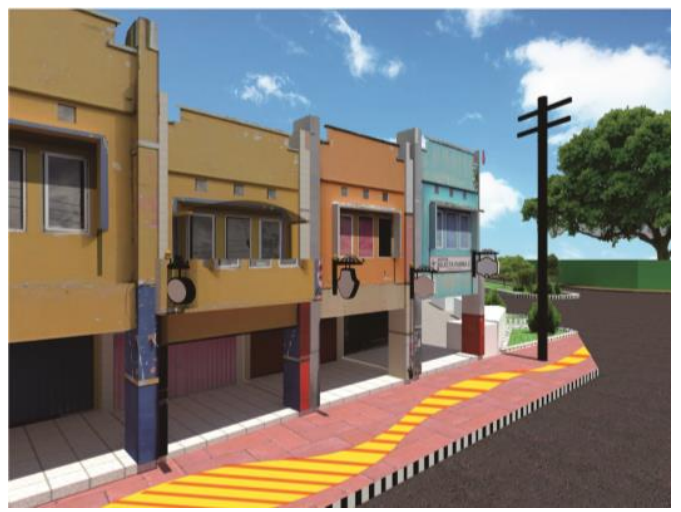

Gambar 5. Rancangan Pedestrian dan Fasad Ruko-Ruko Jalan Cokroaminoto Sumber: Analisis Penulis (2018)

Area shelter dan billboard pada kondisi eksisting diredesain dengan mengangkat tema heritage. Area shelter diberikan peneduh, tempat duduk, serta berfungsi pula sebagai media informasi kuliner dan oleh-oleh khas Malang di sekitar kawasan tersebut. Papan biilboard difungsikan sebagai media promosi pariwisata Kota Malang, baik kuliner, souvenir, atraksi musik, demo memasak, dan pertunjukan live lainnya khususnya di kawasan Klojen Kuliner Heritage.

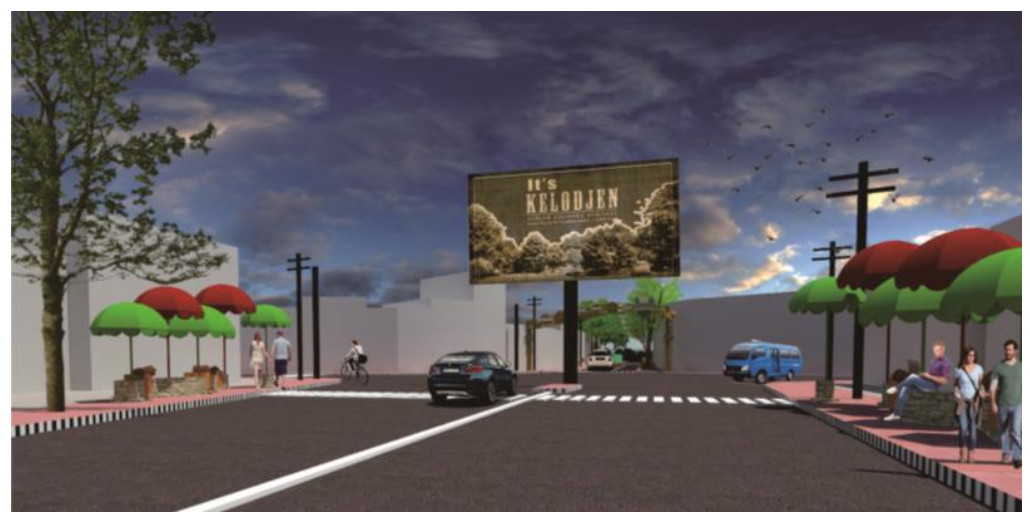

Gambar 6. Main Gate Jl. Cokroaminoto

Sumber: Analisis Penulis (2018)

Gerbang masuk pada Jl. Dr. Sutomo sebagai area sentra kuliner dan souvenir khas Malang dapat dilihat pada gambar 7 dengan mengangkat tema kuliner heritage sebagai konsep utama desain. 


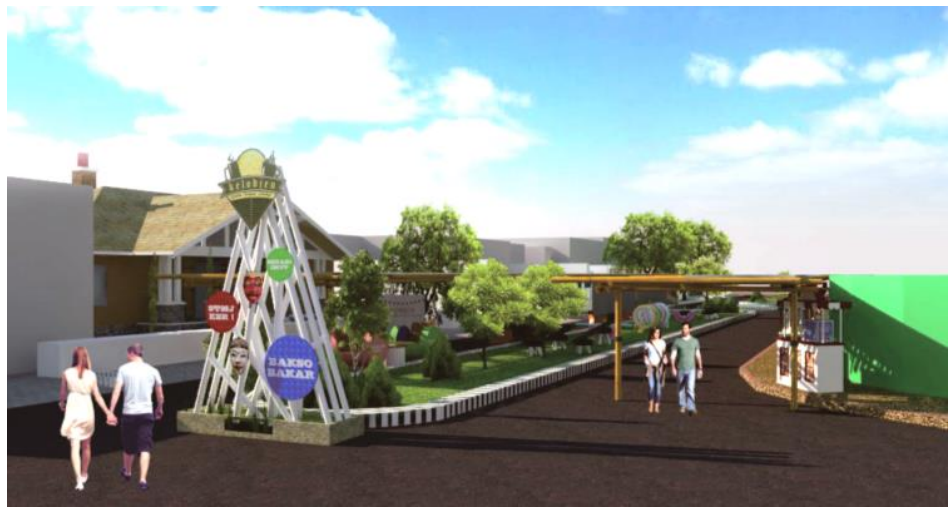

Gambar 7. Main Gate pada Jl. Doktor Sutomo

Sumber: Analisis Penulis (2018)

Area boulevard difungsikan pula sebagai taman bermain anak selain untuk penghijauan dan area resapan air. Pemberian spot foto, area makan, dan point of interest pada lokasi eksisting pohon beringin di kawasan JI. Dr. Sutomo berfungsi sebagai elemen penunjang yang didesain dengan unik tanpa mengabaikan nuansa heritage. Pengalaman ruang yang berbedabeda di spot tertentu diupayakan untuk meminimalisir kejenuhan pengunjung dengan desain yang monoton.
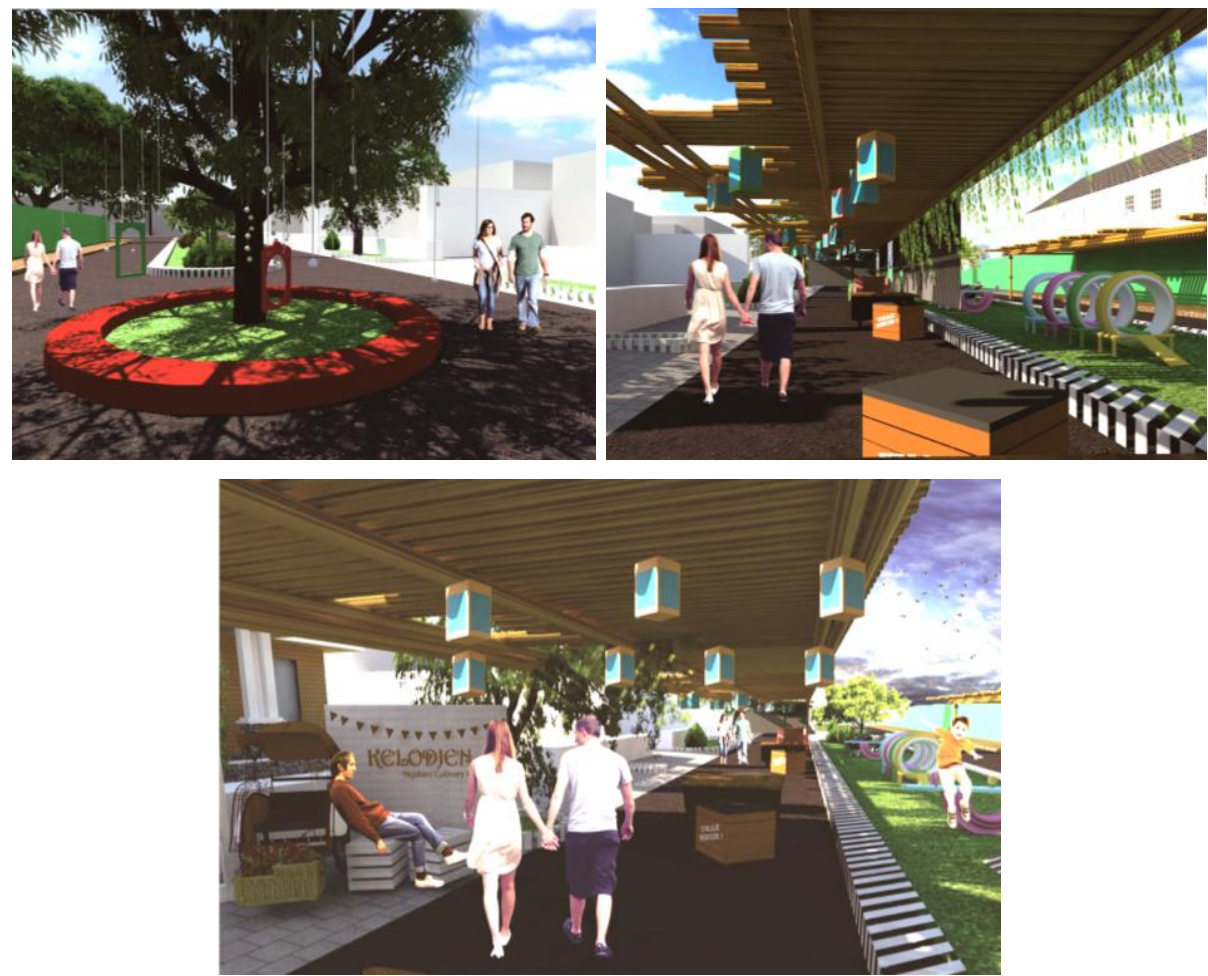

Gambar 8.12 Area Foodcourt dan Playground Sumber: Analisis Penulis (2018)

PAWON: Jurnal Arsitektur, Nomor 02 Volume III, Juli-Desember 2019, ISSN 2597-7636 
Penggunaan material ringan dengan desain portable untuk booth makanan dan souvenir, serta panggung kreasi memudahkan perawatan dan operasional pengelola dalam pemeliharaan sarana prasarana. Penyediaan panggung kreasi dapat difungsikan sebagai tempat atraksi demo memasak, musik, maupun pertunjukan lain yang dapat merubah citra area JI. Dr. Sutomo yang awalnya rawan tindak kejahatan dan maksiat berubah menjadi ruang terbuka positif yang bermanfaat bagi banyak orang. Pemerintah dan komunitas dapat berkolaborasi dengan manajemen hotel dalam pengelolaan area ini untuk meningkatkan promosi Klojen Kuliner Heritage dalam memperkuat citra Kota Malang sebagai kota wisata sehingga kunjungan wisatawan makin bertambah dengan menikmati salah satu pilihan wisata tengah kota.

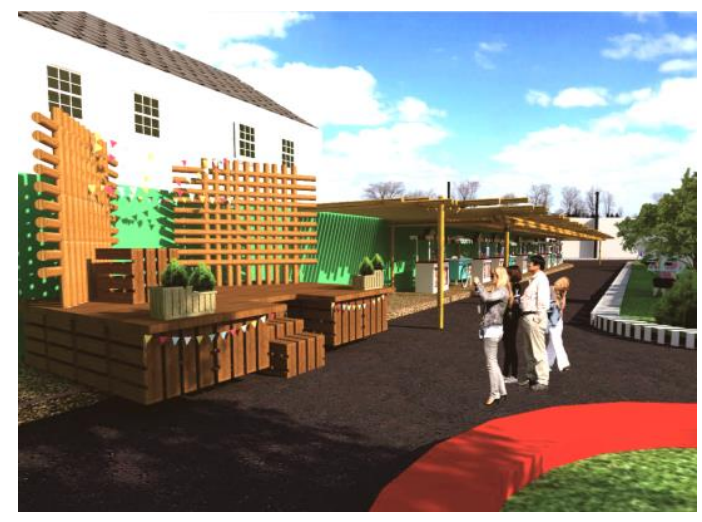

Gambar 9. Konsep desain panggung kreasi dan booth kuliner dan souvenir Sumber: Analisis Penulis (2018)

\section{KESIMPULAN}

Penataan fisik kawasan objek studi sepanjang Jl. Trunojoyo hingga Jl. Dr. Sutomo dilakukan dengan pendekatan desain urban heritage tourism. Kawasan objek studi dijadikan sebagai ruang terbuka aktif, edukatif, rekreatif, dan inovatif untuk memperkuat citra kawasan sebaga Klojen Kuliner Heritage. Strategi penataan konsep desain fisik kawasan difokuskan pada pemberian gerbang masuk destinasi wisata, shelter, billboard, elemen penanda, street furniture bernuansa heritage, perbaikan pedestrian khususnya area sepanjang Jl. Trunojoyo, serta pemberian booth kuliner dan souvenir khas Malang, spot-spot foto, dan panggung kreasi sebagai area atraksi di area Jl. Dr. Sutomo.

Keterlibatan seluruh pemangku kepentingan, baik pemerintah, praktisi, akademisi, pelaku usaha, industri, komunitas, dan media sangat penting untuk terus dibangun dan berperan aktif secara langsung sebagai upaya keberlanjutan pembangunan fisik kawasan yang sinergis dalam 
menciptakan destinasi wisata Klojen Kuliner Heritage. Konsep desain yang dirancang diharapkan dapat ditindaklajuti hingga tahap pelaksanaan.

\section{DAFTAR PUSTAKA}

Dimyati. 2011. Kelompok Aktivitas Masyarakat Di Lingkungan Perkotaan - Studi Kasus: Kegiatan Ekonomi di Lingkungan Pasar Tanah Abang Jakarta. Proceeding Environment Talk: Toward Better Green Living: 28-35.

Hong, J. dan Shin, S. 2016. A Study on Infrastructure-centered Publicness in Urban Public Space through a Look at Dutch Architectural Policies and Practices. Journal of Asian Architecture and Building Engineering. 15 (1): 33-40.

Meng, X. W. dan Setoguchi, T. 2010. Development of Urban Design Guidelines with Wind Tunnel Simulations for Downtown Districts in Winter Cities - New Urban Design Approaches for Cold Region Cities. Journal of Asian Architecture and Building Engineering. 9 (2): 355-362.

Patil, R., dan Patil, V. 2016. Theory of Good City Form by Kevin Lynch-Review. International Journal of Innovative Research in Science, Engineering and Technology. 05 (01): 1172-1174.

Prabowo, B.N. (2015). Kajian Citra Kota dalam City-Branding Magelang Kota Sejuta Bunga. Jurnal MODUL, 15 (2), 163-170.

Pramitasari, P. H., et al. 2018. Studi Kelayakan Kelurahan Klojen sebagai Pusat Wisata Kuliner Heritage Kota Malang. Jurnal PAWON. 02 (01): 49-58. 